\title{
Changes of enzymatic antioxidant system in the small intestine of rats after the chronic invasion by Hymenolepis diminuta (Cestoda, Hymenolepididae)
}

\author{
H. CZECZOT ${ }^{1}$, M. SKRZYCKI ${ }^{1}$, M. MAJEWSKA ${ }^{1}$, M. PODSIAD ${ }^{1}$, R. SALAMATIN ${ }^{2}$, J. TWAROWSKA $^{2}$, \\ B. GRYTNER-ZIĘCINA ${ }^{2}$
}

\begin{abstract}
${ }^{1}$ Chair and Department of Biochemistry, Medical University of Warsaw, Banacha 1, 02-097 Warsaw, Poland, E-mail: hanna.czeczot@wp.pl; ${ }^{2}$ Department of General Biology and Parasitology, Medical University of Warsaw, Chałubinskiego 5, 02-004 Warsaw, Poland
\end{abstract}

\begin{abstract}
Summary
The aim of this study was to evaluate changes in the enzymatic antioxidant system in rat small intestine caused by invasion of tapeworms Hymenolepis diminuta. The study material consisted of samples of the rats small intestine after short- (1.5-months) and long-term (1.5-years) larvae invasion of tapeworm $H$. diminuta. In tissue extracts the concentration of oxidative stress markers (GSH and TBARS) and activity of antioxidant enzymes (SOD, CAT, total GSHPx, SeGSHPx, GST and GSHR) were determined. Changes demonstrated for GSH and TBARS level and the activity of antioxidant enzymes in the small intestine in rats indicate the induction of oxidative stress and weakening of antioxidant defense mechanisms, after both short- and long-term invasion of $H$. diminuta tapeworms. Observed profile of antioxidant enzymes activity in the small intestine of rats after prolonged exposure to direct or indirect contact with $H$. diminuta tapeworms points to the adaptation of the definitive host to oxidative stress and defense against parasitic invasions.
\end{abstract}

Keywords: Hymenolepis diminuta invasion; small intestine of the definitive host; oxidative stress; markers of oxidative stress; antioxidant enzymes

\section{Introduction}

It is clear that in the course of parasitic invasion phagocytic host cells are activated. These cells produce reactive oxygen species (ROS) (Barnes, 1990; Conner \& Grisham, 1996; Dzik, 2006). An important protective function, inhibiting harmful effects of ROS produced by immune response effector cells in small intestine of the host, is played by anti-oxidative enzymes (superoxide dismutase, catalase, peroxidase, glutathione transferase and reductase) and small-molecule anti-oxidants, e.g. GSH. Activity of enzymatic and non-enzymatic anti-oxidative system is a very important factor, assuring protection of small intestine mucous membrane in the host from the effects of oxidative stress accompanying inflammatory reaction (Conner \& Grisham 1996; Gate et al., 1999; Oshima et al., 2003).

Inflammatory reaction induced by parasites in alimentary tract, especially in the small intestine of definitive host, is an expression of specific and intensified biochemical response not only at the local but also systemic level (Machnicka-Rowinska \& Dziemian, 2003; Klion \& Nutman, 2004). Intensity of inflammatory process, occurring in the mucous membrane of host's small intestine invaded by parasites, depends on efficiency of defense mechanisms of the organism, which limit the extent of changes. Also, the type of invasion is important, especially the time of small intestine exposition to direct and/or indirect contact with the parasite (Barnes, 1990; Shin et al., 2009).

In light of current state of knowledge, the above relations apply also to parasitoses, in which the presence of the parasite does not induce significant anatomopathological changes in alimentary tract. Hymenolepis diminuta seems to be such an example. $H$. diminuta is a parasite of many species of rodents, especially mice and rats. It is mildly pathogenic for the host. H. diminuta invasions are mild, without clear clinical symptoms (Milazzo et al., 2010).

However experimental research performed in rats demonstrates that these invasions are accompanied by pathological changes in the mucous membrane of small intestine, such as: inflammatory infiltrations, flattening and shortening of intestinal villi, absorption disturbances, ion transport disturbances (Mettrick, 1980; Fal \& Czaplicka, 1991; Starke \& Oaks, 2001; Kosik-Bogacka et al., 2010). In invaded rats the following effects were noted in small intestine: higher number of mucous cells, compromised intestinal motility and decreased rate of bowel transit. After 32 days since invasion, mastocytosis, or increased number of mast cells, was observed in mucous membrane of intestine, as well as hypertrophy of smooth muscle layer (Dwinell et al., 1994; 1997; 1998). These changes were 
noted in all parts of alimentary tract, which is connected with relatively large dimensions of the parasite and its migration through the intestine in circadian cycle, in response to food ingestion by the host (Podesta \& Mettrick, 1977). In spite of that, invaded rats live long and tapeworms, in the case of invasions not leading to overpopulation, remain in the intestines of the rat until its death, what may prove mutual adaptation in the setting parasite-host.

Because the course of Hymenolepis diminuta parasitosis and range of adaptation of the host to parasitic invasion are not completely elucidated, the research aimed at evaluating changes in enzymatic anti-oxidative system of small intestine of rats, caused by $H$. diminuta invasion, with special consideration of old individuals, after long-lasting invasion.

\section{Material and methods}

\section{Chemicals}

Chemicals used in biochemical studies were purchased from the following sources: 5,5'-dithiobis-(2-nitrobenzoic acid) (DTNB), reduced glutathione (GSH), oxygenated glutathione (GSSG), thiobarbituric acid, sulfosalicylic acid, hydrogen peroxide, cumene peroxide, glutathione reductase, Tris base from Sigma; NADPH from MP Biomedicals, LCC. All nonorganic and other chemicals used in experiments were purchased from POCH (Polskie Odczynniki Chemiczne) Gliwice (Poland).

\section{Animals}

The study was performed on 12 sexually mature male Lew/Han rats (aged $8-10$ weeks). Animals were divided into 4 groups (each consisting of 3 rats). Two groups were subjected to infestation with Hymenolepis diminuta larvae, lasting 1.5 months and 1.5 years. Animals were invaded per os with $H$. diminuta cysticercoids, isolated from body cavity of intermediate host Tribolium destructor. Maturity of tapeworms was confirmed by searching for $H$. diminuta eggs in coproscopic examination. The other two groups were control, consisting of rats not invaded with $H$. $d i$ minuta tapeworm larvae.

Rats exposed to short- and long-term invasion of tapeworms and control rats during quarantine (2 weeks) and during the course of the study, remained in controlled laboratory conditions and were fed standard feed (Labofeed H) with ad libitum access to water. After the conclusion of experiments, rats were sacrificed by intraperitoneal injection of Morbital. Small intestine was isolated from each rat and put into chilled $0.9 \% \mathrm{NaCl}$. Tapeworms were removed from isolated intestines and fragments of intestines were sampled. Taking into consideration the ability of $H$. diminuta to move throughout alimentary tract, in the case of infested rats we harvested this part of intestine, where scolex and proximal part of the tapeworm was located (immature segments, developing organs) as well as the fragment of small intestine, where tapeworms' strobila was not found. At the same time, middle part of small intestine was taken from control rats. Each part sampled for examinations constituted $1 / 3$ of the whole length of small intestine. This method of sampling host's small intestine with or without strobila of $H$. diminuta for examinations enabled the evaluation of parasitic invasion not only on this fragment of intestine, where the parasite was located, but also in all the intestine. Evaluation of oxidative stress parameters and activity of anti-oxidative enzymes in the middle portion of small intestine of rat not infested with $H$. diminuta seems to be the right control for comparison of intestinal anti-oxidative system in the parasite-host setting.

Examinations were approved by the Local Ethical Committee for Experiments on Animals of Warsaw Medical University (Act no. 23, dated October 30, 2007).

Infestation of rats with $H$. diminuta tapeworm larvae, isolation of intestines and tapeworms was performed in the General Biology and Parasitology Department of Warsaw Medical University.

\section{Preparation of tissue extracts}

Immediately after harvesting, fragments of rat's small intestine were washed in $0.9 \% \mathrm{NaCl}$ and frozen in $-70^{\circ} \mathrm{C}$. After thawing, intestines were cut into smaller pieces and homogenized (five times 1 minute each, with 3-minute intervals) in 9 volumes of chilled $100 \mathrm{mM}$ Tris- $\mathrm{HCl}$ buffer (pH 7.5), containing $5 \mathrm{mM} \mathrm{MnCl}, 100 \mathrm{mM} \mathrm{KCl}, 0.5 \mathrm{mM}$ PMSF (phenylmethylsulfonyl fluoride) and 1\% (v/v) Triton X-100, with use of homogenizer Heidolph Diax 600 at $9500-13000$ rotations/minute. Obtained homogenates were subjected to 30-minute extraction on magnetic stirrer, and then frozen in $-70^{\circ} \mathrm{C}$. After 24 hours, homogenates were thawed and centrifuged for 30 minutes in $4^{\circ} \mathrm{C}$ at $12000 \times g$. Obtained supernatants (tissue extracts) were used for biochemical determinations. Prepared supernatants were kept at $-70^{\circ} \mathrm{C}$ until the time of performing biochemical determinations.

\section{Biochemical determinations}

Markers of oxidative stress were determined in supernatants obtained from isolated small intestines of control rats, and after short- and long-term invasion of $H$. diminuta. These determinations included concentration of compounds reacting with thiobarbituric acid (TBARS), evidencing the level of peroxidation of lipids and concentration of reduced glutathione (GSH), as well as activity of anti-oxidative enzymes: superoxide dismutase (SOD1 and SOD2), catalase (CAT), total glutathione peroxidase (tot. GSHPx), selenedependent glutathione peroxidase (SeGSHPx), glutathione transferase (GST) and glutathione reductase (GSHR). Moreover, total protein concentration was estimated. All above determinations were performed in the Chair and Department of Biochemistry of Warsaw Medical University.

\section{Determination of oxidative stress markers}

Lipid peroxidation level was measured with the method of Ohkawa et al. (1979). The method bases on determination of the concentration of substances reacting with thiobarbituric acid (TBARS) - maleic dialdehyde (MDA) and other, secondary lipid peroxidation products. 
Concentration of reduced glutathione (GSH) was determined on the basis of method elaborated by Ellman (1959) and Sedlak \& Lindsay (1968). This method uses formation of a color product, which is formed in the reaction of GSH with 5,5'-dithiobis-(2-nitrobenzoic acid) (DTNB).

\section{Determination of anti-oxidative enzyme activity}

Activity of copper zinc superoxide dismutase (SOD1) (EC 1.15.1.1) was determined with use of RANSOD kit from RANDOX (Great Britain). In this method, superoxide radical anion is formed in the reaction of xanthine with xanthine oxidase, which in turn reduces 2-(4-iodophenyl)3-(4-nitrophenyl)-5-phenyltetrazolium chloride, forming colorful formazan.

Activity of manganese superoxide dismutase (SOD2) (EC 1.15.1.1) was determined according to Beauchamp \& Fridovich method (1971), modified by Oberley \& Spitz (1984). Superoxide radical anion formed in the reaction of xanthine and xanthine oxidase, reduces nitro blue tetrazolium chloride - NBT (2,2'-di-p-nitrophenyl-5,5'-diphenyl-3,3'-[3,3'-dimetoxy-4,4'diphenyl]-ditetrazol chloride), forming a colorful complex. Catalase activity (CAT) (EC 1.11.1.6) was determined according to Goth (1999). The method is based on measuring the rate of hydrogen peroxide decomposition.

Total activity of glutathione peroxidase (tot. GSHPx) (EC 1.11.1.9) was determined according to Wendel's method (1981). In this method GSHPx catalyses oxidation of GSH, with participation of cumene superoxide.

Activity of selene-dependent glutathione peroxidase (SeGSHPx) (EC 1.11.1.9) was determined on the basis of method described by Wendel (1981) as well as Paglia \& Valentine (1967). In this method Se-GSHPx catalyses oxidation of GSH with participation of hydrogen peroxide. Activity of S-glutathione peroxidase (GST) (EC 2.5.1.18) was determined according to the method of Habig et al.

A) TBARS

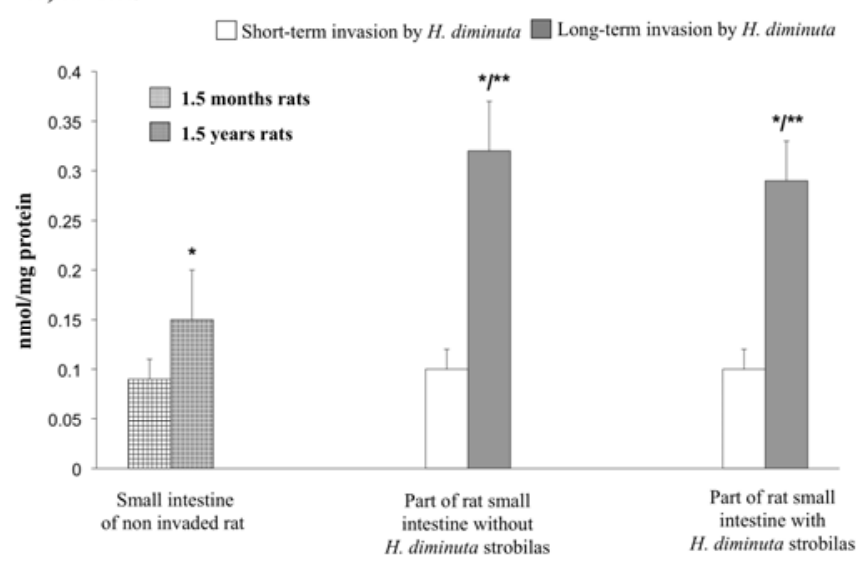

(1974), using 1-chloro-2,4-dinitrobenzene (CDNB) as a substrate.

Activity of glutathione reductase (GSHR) (EC 1.6.4.2) was determined according to the method described by Goldberg and Spooner (1983). Oxidized glutathione was used as a substrate (GSSG).

Concentration of proteins in supernatants was determined according to the method of Bradford (1976). Measurement of absorbance in all determinations were performed on Shimadzu UV 1202 spectrophotometer. Activity of evaluated enzymes was expressed in U/mg of protein. GSH and TBARS concentration was expressed in $\mu \mathrm{mol} / \mathrm{mg}$ of protein and $\mathrm{nmol} / \mathrm{mg}$ of protein, respectively.

\section{Statistical evaluation}

All the results were presented as arithmetic mean from three independent experiments \pm SD. Statistical analysis of obtained results was performed with use of STATISTICA 6.0 software. Differences between arithmetic means were deemed significant, if $\mathrm{p} \leq 0.05$. In order to determine the effect of invasion (presence of tapeworm's strobila in rat intestine) and time of invasion (1.5 months and 1.5 years) on the level of oxidative stress parameters and activity of anti-oxidative enzymes, Anova bifactorial analysis of variance with repeated measurements was performed.

\section{Results}

Lipid peroxidation level (expressed as TBARS concentration) in the small intestine of rats infested for a short time (1.5 months) with $H$. diminuta was similar to control. At the same time, long-term (1.5 years) infestation of rats with $H$. diminuta caused significant $(\mathrm{p} \leq 0.05)$ intensification of lipid peroxidation in small intestine, compared to control. Level of lipid peroxidation in the parts of small intestine with or without $H$. diminuta strobilas was similar.

B) GSH

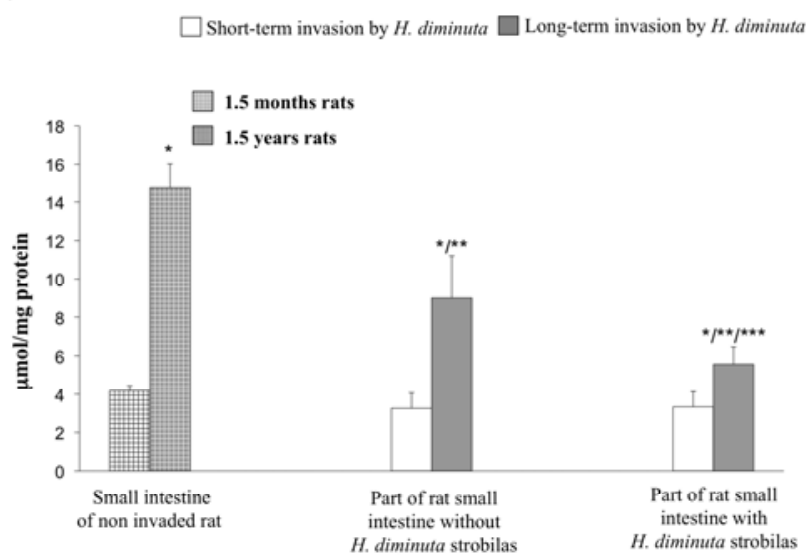

\footnotetext{
Fig. 1. Concentration of TBARS (A) and GSH (B) in the small intestine of rat after short- and long-term invasion by $H$. diminuta tapeworm * - significant versus short-term invasion of rats with $H$. diminuta tapeworm $(\mathrm{p} \leq 0.05)$

** - significant versus small intestine of rat not invaded by $H$. diminuta $(\mathrm{p} \leq 0.05)$

$* * *$ - significant versus part of small intestine of rat without $H$. diminuta strobilas $(\mathrm{p} \leq 0.05)$
} 


\section{(A) Short-term invasion}

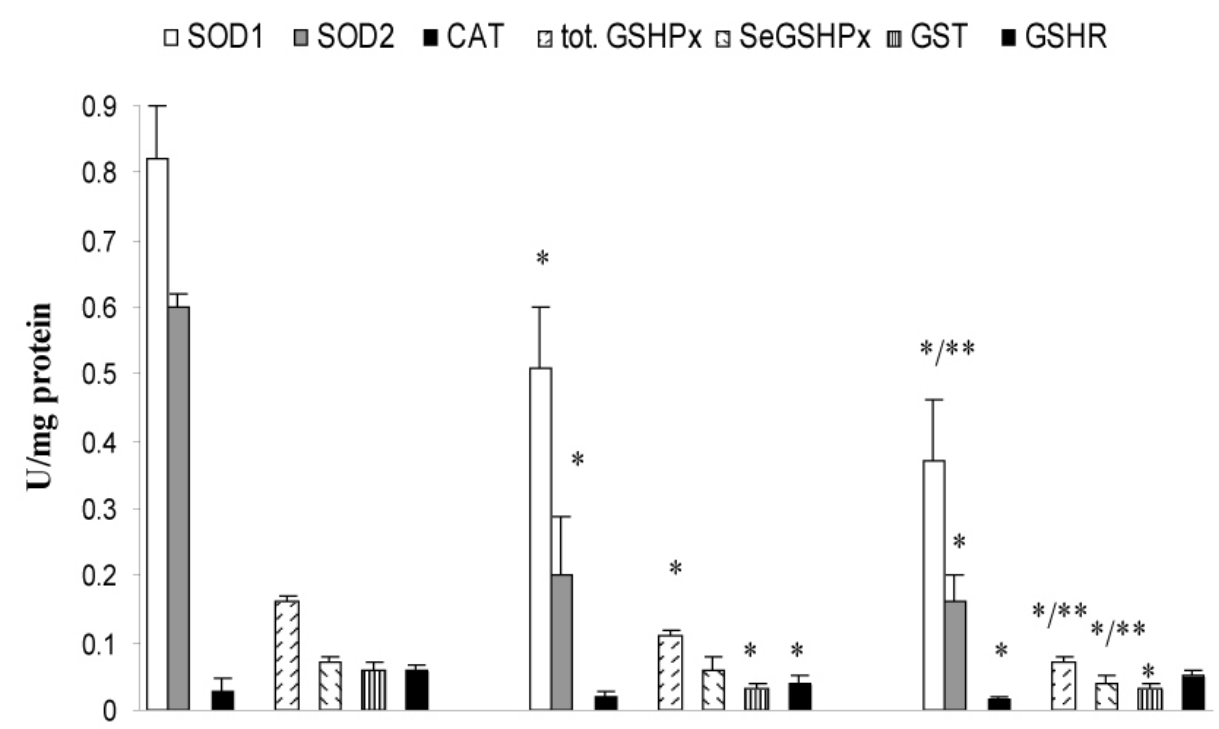

(B) Long-term invasion

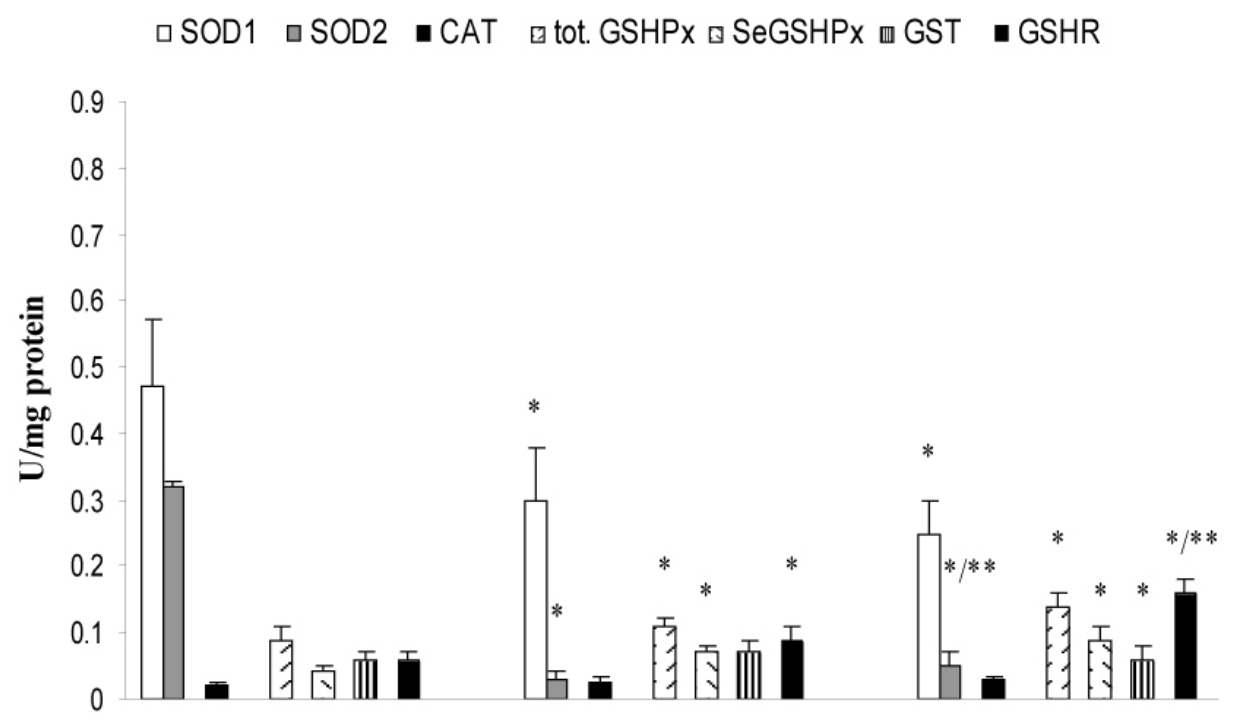

Fig. 2. Influence of short- (A) and long-term (B) exposition to $H$. diminuta tapeworm on the activity of anti-oxidative enzymes in rat's small intestine

* - significant versus small intestine of rats not invaded by $H$. diminuta $(\mathrm{p} \leq 0.05)$;

** - significant versus part of small intestine of rat invaded by H. diminuta without tapeworm's strobilas

Significantly higher level of lipid peroxidation was found in the small intestine of control and infested old rats (over 1.5 -year-old), compared to young rats $(\mathrm{p} \leq 0.05)$ (Fig. 1A). In the case of short-term $H$. diminuta invasion, concentration of GSH was similar in the small intestine of control and in its parts with or without strobilas of the tapeworm. Long-term invasion of rats with $H$. diminuta was accompanied by statistically significant $(\mathrm{p} \leq 0.05)$ decrease of GSH concentration in the whole small intestine, compared to control animals. The highest concentration of GSH was noted in the small intestine of control rats. Just like in the case of lipid peroxidation level, significantly higher GSH concentration was found in the small intestine of old rats ( $p$ $\leq 0.05)$ (Fig. $1 \mathrm{~B}$ ).

After short-time invasion of young rats by $H$. diminuta, in both parts of small intestine (with or without strobilas), significant decrease of activity of evaluated anti-oxidative enzymes was observed (Fig. 2 A).

In the part of rat small intestine without tapeworm's strobilas, significantly lower activity, in comparison to control, 

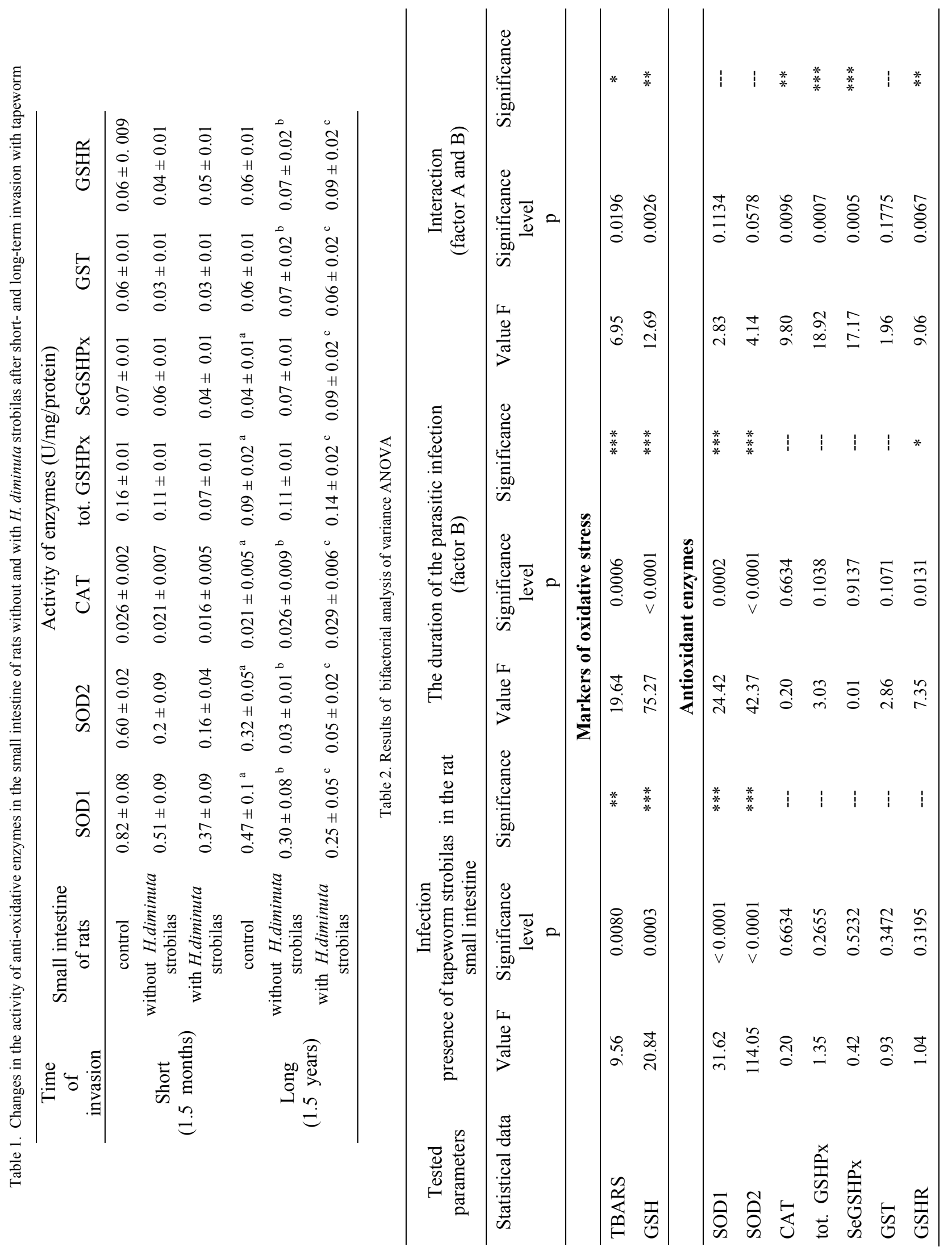
was shown for SOD1, SOD2, total GSHPx, GST and GSHR $(\mathrm{p} \leq 0.05)$.

Statistically significant $(p \leq 0.05)$ decrease of activity of SOD1 and SOD2, CAT, total GSHPx, SeGSHPx and GST was found in the part of small intestine with tapeworm's strobilas, compared to control. GSHR activity in this part was at the level of control.

Comparison of activity of anti-oxidative enzymes between the parts of small intestine with or without strobilas, demonstrated lower activity of SOD1, SOD2, CAT, total GSHPx and SeGSHPx in the part of intestine with a tapeworm. However, observed differences were statistically significant only for SOD1, total GSHPx and SeGSHPx. Activity of other enzymes in both parts of small intestine of rat infested with $H$. diminuta was at the similar level (Table 1 ).

Long-term invasion of rats with $H$. diminuta tapeworm caused statistically significant decrease of SOD1 and SOD2 (especially SOD2) activity in both, infested parts of small intestine. These changes were accompanied, in the part of intestine with strobilas, by statistically significant increase of total GSHPx, SeGSHPx and GSHR activity ( $p$ $\leq 0.05$ ). Additionally SOD2 and GSHR activity was significantly higher in the fragment invaded at the moment by tapeworms (Fig. 2B).

Activity of SOD isoenzymes, especially SOD2, in short time invaded rats was statistically higher than in rats after longterm tapeworm invasion. Long-term presence of the tapeworm caused an increase of activity of CAT and GSHdependent enzymes (total GSHPx, SeGSHPx, GST and GSHR), compared to short-term invasion. At the same time, in the part of small intestine without a tapeworm, decreased activity of both SOD isoenzymes as well as increase of GST and GSHR activity was observed $(\mathrm{p} \leq 0.05)$ (Table 1$)$.

Bifactorial analysis of variance ANOVA employed in our studies, allowed us to evaluate the influence and interactions of $H$ diminuta tapeworm rat invasion and duration of parasitic invasion on the level of oxidative stress markers and changes in activity of anti-oxidative enzymes. Obtained results showed that both invasion of animals with $H$. diminuta tapeworm and length of parasitic invasion and interaction existing between these factors influence the level of oxidative stress markers (TBARS and GSH). Observed effects of changed activity of SOD1 and SOD2 in intestines of animals seem to be the effect of individual activity of each of evaluated factors, while activity of CAT, total GSHPx and SeGSHPx seem to be the effect of simultaneous activity of both factors together. None of evaluated factors influenced activity of GST. Duration of invasion and interaction of both factors decided about the changes of GSHR activity in small intestine of rats invaded by $H$. diminuta (Table 2).

\section{Discussion}

Determination of oxidative stress parameters and activity of anti-oxidative enzymes in small intestine of rats invaded or not by $H$. diminuta, allowed evaluation of changes in enzymatic anti-oxidative system after short- and long-term invasion and establishment of ability of definitive host defense against the effects of parasite existence in alimentary tract, considering its motility in intestines. Especially important and valuable are results of studies concerning parasite-host setting after long-term tapeworm invasion. Results obtained from this study show that the presence of $H$. diminuta tapeworm in small intestine of definitive host induces oxidative stress. It has been found that in the small intestine of young (after 1.5 months of invasion) and old rats (invaded for 1.5 years), a special role in inhibiting ROS is played by superoxide dismutases (SOD1 and SOD2), participating in elimination of superoxide radical anion, precursor of all oxygen radicals and their reactive derivatives. It seems that the activity of SOD in rat's small intestine is completed by total activity of glutathione peroxidase (total GSHPx), inhibiting not only hydrogen peroxide, but also organic superoxides. Participation of other evaluated anti-oxidative enzymes in the defense of small intestine against the effects of oxidative stress is decidedly lower and does not depend on age of rats.

Decrease of SOD1, SOD2 and total GSHPx activity in older animals indicates strong oxidative stress and attenuation of anti-oxidative defense mechanisms. This is reflected in elevated levels of lipid peroxidation (TBARS) and significant increase of concentration of reduced glutathione (GSH). It is known that in physiological conditions, GSH is not only a co-substrate for the enzymes of glutathione redox cycle, but also fulfils the function of cellular "thiol buffer", which very effectively counteracts effects of -SH group oxidation. This prevents the loss of biological activity of many functional cell proteins (Hayes \& McLellan, 1999; Sies, 1999; Sen, 2000; Pastore et al., 2003). High concentration of GSH in small intestine of rats after 1.5 years of experiment, with relatively low activity of GSH-dependent enzymes, points to its participation in direct scavenging of free radicals (Sies, 1999).

Short-term invasion of rat by $H$. diminuta tapeworm, causing oxidative stress in the host, may promote inflammatory changes in host's small intestine. This is confirmed by low activity of evaluated anti-oxidative enzymes, especially in the part of small intestine that is exposed to direct contact with the parasite. Decrease of activity of anti-oxidative enzymes in the small intestine of invaded rats, compared to the rats from the control group, may be caused by disturbed balance of oxidation and reduction processes, as well as loss of the ability to inhibit ROS. Unfortunately, this leads to higher inefficiency of enzymatic anti-oxidative system (Conner \& Grisham, 1996; Gate et al., 1999). Chronic presence of tapeworms in the small intestine of rats disturbs the pro-oxidative/anti-oxidative balance. This fact is evidenced by the fall of GSH concentration, elevated level of lipid peroxidation and significant decrease of SOD1 and SOD2 activity, which is accompanied by the increase of activity of CAT, total GSHPx, SeGSHPx and GSHR in the part of small intestine with $H$. diminuta strobilas. Observed differences in the level of evaluated parameters in the small intestine of infested rats, compared to the intestine of control rats, show oxidative stress and 
further excitation of pro-oxidative processes in the cells of intestinal mucosa.

Early and secondary mediators released in these processes, such as cytokines, interleukins (IL1-IL18); interferons (IFN-a, b, g); tumor necrosis factor (TNF-a, TNF-b), arachidonic acid metabolites (prostaglandins, leukotrienes, thromboxanes) and ROS formed in excess, may damage the cells of mucosa (Dzik, 2006).

Decreased activity of SOD1 and SOD2, being the key enzymes of anti-oxidative system, may be caused by the disturbances in the balance between the processes forming and inhibiting ROS. Superoxide dismutase, decomposing superoxide radical anion, prevents formation of other reactive oxygen derivatives, which hinder triggering cascade of unfavorable biological cellular phenomena by ROS (e.g. lipid peroxidation, protein oxidation, DNA mutations) (Fridovich, 1997; Zelko et al., 2002; Fattman et al., 2003). Accumulation of high amounts of ROS resulting from superoxide radical anion, fosters further changes in the small intestine. Increase of activity of CAT, total GSHPX and SeGSHPx, responsible for elimination of hydrogen peroxide or lipid peroxides in the small intestine of rat, after long-term tapeworm infestation, points to defense of host intestinal mucous cells against the lesions caused by ROS accumulation. At the same time, high activity of GSHR in the small intestine of rats with tapeworms, documents involvement of this enzyme in regeneration of reduced GSH from oxygenated glutathione (GSSG). The presence of GSH is necessary in reactions catalyzed by GSH-dependent enzymes. This indicates close relationship of defense mechanisms in the small intestine of the host during $H$. diminuta invasion.

Long-term (1.5 years) presence of parasites in the small intestine of rats, compared to shorter time of their direct contact (1.5 months), clearly shows the change in antioxidative profile in the small intestine of the host. In chronic invasion of rats by $H$. diminuta, attention is brought to significant decrease of SOD1 and SOD2 activity, as well as elevation of activity of CAT and GSHdependent enzymes, in the part of small intestine exposed to direct contact with the tapeworm (the part of rat's small intestine containing strobilas of the tapeworm). In the part of rat's small intestine without strobilas of the tapeworm, or in the part not exposed to direct contact of the parasite with the host organism, activity of SOD1 and SOD2 is decreased, while activity of GST and GSHR increases significantly. Activity of other anti-oxidative enzymes (CAT, total GSHPx, SeGSHR) remains at the same level, as in the small intestine of rats after short-term invasion. Increase of activity of GSH-dependent enzymes points to their participation not only in decomposition of hydrogen peroxide, but also organic superoxides and endo- and exogenous electrophilic compounds.

Changes of GSH and TBARS level, as well as increase of activity of GSH-dependent enzymes, especially GST and GSHR, in the small intestine of rats, both in the case of short- and long-term invasion, indicate oxidative stress. GST is an enzyme responsible for the formation of S-con- jugates with endo- and exogenous electrophilic compounds from GSH, including lipid peroxidation products, which leads to their inactivation and decrease of toxicity. At the same time, GSHR regenerates the pool of reduced form of glutathione in the cell.

Observed increased level of lipid peroxidation, differences in GSH concentration and activity of anti-oxidative enzymes in the small intestine of rat exposed to short-term invasion by the tapeworm, compared to longer time of exposition of small intestine mucous membrane to parasite, indicate gradual depletion of anti-oxidative defense mechanisms. Meanwhile, increase of activity of GSHdependent enzymes, especially GST and GSHR, in the small intestine exposed for a longer time to direct contact with the tapeworm, suggests adaptation of mucous cells to functioning in the conditions of oxidative stress.

Inefficiency of anti-oxidative system hinders ROS elimination in the small intestine, which limits its ability to function in the conditions of oxidative stress occurring in the result of $H$. diminuta invasion.

Results obtained in this study confirm also recently published data, indicating that in the course of $H$. diminuta invasion, impairment of anti-oxidative defense mechanisms occurs in the small intestine of rat, which may cause changes typical for parasitic invasions (Shin et al., 2009; Kosik-Bogacka et al., 2011).

\section{Conclusions}

Observed changes in the level of GSH and TBARS as well as activity of anti-oxidative enzymes indicate that shortterm and chronic exposition of rat's small intestine to direct contact with the tapeworm (parts of small intestine with $H$. diminuta strobilas or without them), leads to attenuation of anti-oxidative defense mechanisms. Profile of activity of anti-oxidative enzymes in the small intestine of rats after long-term $H$. diminuta tapeworm invasion suggests adaptation of the definitive host organism to oxidative stress and defense against results of parasitic invasion.

\section{References}

BARNES, P. J. (1990): Reactive oxygen species and airway inflammation. Free Radic. Biol. Med., 9: 235 - 243. DOI: 10.1016/0891-5849(90)90034-G

BeAuchamp, CH., Fridovich, I. (1971): Superoxide dismutase: improved assays and assay applicable to acrylamide gels. Anal. Biochem., 44: 276 - 287

BRADFORD, M. (1976): A rapid and sensitive method for the quantitation of microgram quantities of protein utilizing the principle of protein dye binding. Anal. Biochem., 72: $248-254$

CONNER, E. M., Grisham, M. B. (1996): Inflammation, free radicals and antioxidants. Nutrition, 12: $274-277$

DWINELL, M. B., BASS, P., OAKS, J. A. (1994): Intestinal myoelectric alterations in rats chronically infected with the tapeworm Hymenolepis diminuta. Am. J. Physiol., 267: $851-858$ 
Dwinell, M. B., BAss, P., Schaefer, D. M., OAKs, J. A. (1997): Tapeworm infection decreases intestinal transit and enteric aerobic bacterial populations. Am. J. Physiol., 273: $480-485$

Dwinell, M. B., Wise, R. M., Bass, P., OAKs, J. A. (1998): Hymenolepis diminuta: mucosal mastocytosis and intestinal smooth muscle hypertrophy occur in tapeworminfected rats. Exp. Parasitol., 89: $92-102$

DzIK, J. M. (2006): Molecules released by helminthes parasites involved in host colonization.

Acta Bioch. Pol., 53: $33-64$

Ellman, G. L. (1959): Tissue sulfhydryl groups. Arch. Biochem. Biophys., 82: 70 - 77. DOI: 10.1016/00039861(59)90090-6

FAL, W., CzAPliCKA, H. (1991): Effect of experimental hymenolepiasis on various tissue reactions in rats. Wiad. Parazytol., 37: $331-342$

Fattman, C. L., Schafter, M., Oury, T. D. (2003): Extracellular superoxide dismutase in biology and medicine. Free Rad. Biol. Med., 35: 226 - 256. DOI: 10.1016/S0891-5849(03)00402-7

FRIDOVICH, I. (1997): Superoxide anion radical $\left(\mathrm{O}_{2}^{-}\right)$, superoxide dismutases, and related matters. J. Biol. Chem., 272: 18515 - 18517. DOI: $10.1074 /$ jbc. 272.30 .18515

Gate, L., Paul, J., Nguuyen, B. A., Tew, K., Tapiero, H. (1999): Oxidative stress induced in pathologies: the role of antioxidants. Biomed. Pharmacotherapy, 53: $169-180$. DOI: $10.1074 /$ jbc.272.30.18515

GOLDBERG, D. M., SPOONER, R. J. (1983): Glutathione reductase. In: Bergmeyer H. V. (Ed) Methods of Enzymatic Analysis. Volume 3. Verlag Chemie, Weinheim, pp. $258-265$

Goth, L. (1999): A simple method for determination of serum catalase activity and revision of reference range. Clin. Chim. Acta., 196: 143 - 151

HABIG, W. H., PABST, M., JACOBY, W. (1974): Glutathione S-transferase, the first step in mercapturic acid formation. J. Biol. Chem., 249: 7130 - 7139

Hayes, J. D., MClellan, L. I. (1999): Glutathione and glutathione-dependent enzymes represent a coordinately regulated defence against oxidative stress. Free Rad. Res., 31: 273 - 300. DOI: 10.1054/drup.1999.0083

KLION, A. D., NUTMAN, T. B. (2004): The role of eosinophils in host defense against helminth parasites. J. Aller. Clin. Immunol., 113: 30 - 37. DOI: 10.1016/j.jaci.2003.10.050

KosiK-Bogacka, D. I., Baranowska-Bosiacka, I., SALAMATIN, R. (2010): Hymenolepis diminuta: effect of infection on ion transport in colon and blood picture of rat. Exp. Parasitol., 124: 285 - 294. DOI: 10.1016/j.exppara.2009.10.014

KosIK-BOGACKA, D.I., BARANOWSKA -BOSIACKA, I., NoceŃ, I., JAKUBOWSKA, K. (2011): Hymenolepis diminuta: Activity of anti-oxidant enzymes in different parts of rat gastrointestinal tract. Exp. Parasitol., 128(3): 265271. DOI: 10.1016/j.exppara.2010.09.001

MACHNiCKA-RowiŃSKA, B., DZIEMIAN, E. (2003): Eosynophils in parasitic infections - clinical and functional significance. Wiad. Parazytol., 49: 245 - 254

RECEIVED SEPTEMBER 12, 2011
METTRICK, D. F. (1980): The intestine as an environment for Hymenolepis diminuta. In: ARAI H. P. (Ed)) Biology of the tapeworm Hymenolepis diminuta. (Academic Press, New York, pp. $281-356$

Milazzo, C., Ribas, A., Casanova, J. C., Cagnin, M., GERACI, F., Di BELLA, C. (2010): Helminths of the brown rat (Rattus norvegicus) (Berkenhout, 1769) in the city of Palermo, Italy. Helminthologia., 47(4): 238 - 240. DOI: 10.2478/s11687-010-0037-4

OBERLEY, L. W., SpITZ, D. R. (1984): Assay of superoxide dismutase activity in tumor tissue. Meth. Enzymol., 105: 457 - 464. DOI: 10.1016/S0076-6879(84)05064-3

OHKawA, H., OHISHI, N., YAGI, K. (1979): Assay for lipid peroxides in animal tissues by thiobarbituric acid reaction. Anal. Biochem., 95: 351 - 358. DOI: 10.1016/00032697(79)90738-3

Oshima, H., TAdemichi, M., SAwa, T. (2003): Chemical basis of inflammation - induced carcinogenesis. Arch. Biochem. Biophys., 417: 3 - 11

Paglia, D., Valentine, W. (1967): Studies on the quantitative and qualitative characterization of erythrocytes glutathione peroxidase. J. Lab. Clin. Med., 70: 158 - 168

Pastore, A., Fedrici, E., Bertini, F., Piemonte, S. (2003): Analysis of glutathione: implication in redox and detoxification. Clin. Chim. Acta., 33: 19 - 39. DOI: 10.1016/S0009-8981(03)00200-6

Podesta, R. B., MetTrick, D. F. (1977): Proximal-distal absorptive gradients in the in vivo intestine of normal and infected (Hymenolepis diminuta:Cestoda) rats. Canad. J. Physiol. Pharm., 55: 791 - 803. DOI: 10.1139/y77-107

SEDLAK, J., LINDSAY, R. H. (1968): Estimation of total, protein-bound, and nonprotein sulfhydryl groups in tissue with Ellman's reagent. Anal. Biochem., 25: 192 - 205. DOI: 10.1016/0003-2697(68)90092-4

SEN, C. K. (2000): Biological thiols and redox-regulated signal transduction. Curr. Top. Cell. Regul., 36: $1-30$. DOI: 10.1016/B978-044482650-3/50015-8

ShIN, M. H., LEE, Y. A., MIN, D. Y. (2009): Eosinophilmediated tissue inflammatory responses in helminth infection. Korean J. Parasitol., 47 Suppl.: 125 - 131. DOI: 10.3347/kjp.2009.47.S.S125

SIES, H. (1999): Glutathione and its cellular functions. Free Radic. Biol. Med., 27: 916 - 921. DOI: 10.1016/S08 91-5849(99)00177-X

STARKE, W. A., OAKS, J. A. (2001): Ilea mucosal mast cell, eosinophil, and goblet cell populations during Hymenolepis diminuta infection of the rat. J. Parasitol., 87:1222 - 1225. DOI: $10.2307 / 3285276$

Wendel, A. (1981): Glutathione peroxidase. Meth. Enzymol., 77: 325 - 333. DOI: 10.1016/S0076-6879(81)77046-0 ZELKO, I. N., MARIANI, T. J., FolZ, R. J. (2002): Superoxide dismutase multigene family: a comparison of the CuZn-SOD (SOD1), Mn-SOD (SOD2), and EC-SOD (SOD3) gene structures, evolution, and expression. Free Radic. Biol. Med., 33: 337 - 349. DOI: 10.1016/S0891 5849(02)00905-X

ACCEPTED JULY 27, 2012 